CHRONIC OBSTRUCTIVE PULMONARY DISEASE

\title{
Creatine supplementation during pulmonary rehabilitation in chronic obstructive pulmonary disease
}

\author{
J P Fuld, L P Kilduff, J A Neder, Y Pitsiladis, M E J Lean, S A Ward, M M Cotton
}

Thorax 2005;60:531-537. doi: 10.1136/thx.2004.030452

See end of article for authors' affiliations

Correspondence to: Dr J P Fuld, Department of Cystic Fibrosis and Lung Defence, Papworth Hospital, Papworth Everard, Cambridgeshire CB3 8RE, UK; i.fuld@dsl. pipex.com

Received 20 June 2004 Accepted 2 March 2005
Background: Skeletal muscle wasting and dysfunction are strong independent predictors of mortality in patients with chronic obstructive pulmonary disease (COPD). Creatine nutritional supplementation produces increased muscle mass and exercise performance in health. A controlled study was performed to look for similar effects in 38 patients with COPD.

Methods: Thirty eight patients with COPD (mean (SD) forced expiratory volume in 1 second $\left(\mathrm{FEV}_{1}\right) 46$ (15)\% predicted) were randomised to receive placebo (glucose polymer $40.7 \mathrm{~g}$ ) or creatine (creatine monohydrate $5.7 \mathrm{~g}$, glucose $35 \mathrm{~g}$ ) supplements in a double blind trial. After 2 weeks loading (one dose three times daily), patients participated in an outpatient pulmonary rehabilitation programme combined with maintenance (once daily) supplementation. Pulmonary function, body composition, and exercise performance (peripheral muscle strength and endurance, shuttle walking, cycle ergometry) took place at baseline $(n=38)$, post loading $(n=36)$, and post rehabilitation $(n=25)$.

Results: No difference was found in whole body exercise performance between the groups: for example, incremental shuttle walk distance mean $-23.1 \mathrm{~m}(95 \% \mathrm{Cl}-71.7$ to 25.5$)$ post loading and $-21.5 \mathrm{~m}$ $(95 \% \mathrm{Cl}-90.6$ to 47.7$)$ post rehabilitation. Creatine increased fat-free mass by $1.09 \mathrm{~kg}(95 \% \mathrm{Cl} 0.43$ to $1.74)$ post loading and $1.62 \mathrm{~kg}(95 \% \mathrm{Cl} 0.47$ to 2.77$)$ post rehabilitation. Peripheral muscle performance improved: knee extensor strength $4.2 \mathrm{~N} \cdot \mathrm{m}(95 \% \mathrm{Cl} 1.4$ to 7.1$)$ and endurance $411.1 \mathrm{~J}(95 \% \mathrm{Cl} 129.9$ to 692.4) post loading, knee extensor strength $7.3 \mathrm{~N} . \mathrm{m}(95 \% \mathrm{Cl} 0.69$ to 13.92) and endurance $854.3 \mathrm{~J}$ (95\% Cl 131.3 to 1577.4) post rehabilitation. Creatine improved health status between baseline and post rehabilitation (St George's Respiratory Questionnaire total score -7.7 (95\% Cl -14.9 to -0.5$)$ ).

Conclusions: Creatine supplementation led to increases in fat-free mass, peripheral muscle strength and endurance, health status, but not exercise capacity. Creatine may constitute a new ergogenic treatment in COPD.
$\mathrm{T}$ he muscle wasting and impaired muscle function associated with chronic obstructive pulmonary disease (COPD) are predictors of handicap, disability and increased mortality. ${ }^{1}$ Wide ranging strategies have been used in an attempt to restore muscle mass such as nutritional supplements, ${ }^{2}{ }^{3}$ recombinant human growth hormone, ${ }^{4}$ anabolic steroids, ${ }^{5}$ and appetite stimulants. ${ }^{6}$ Despite the weight gain achieved with most of these strategies, improvements in muscle strength or in measures of whole body exercise performance have not been demonstrated. In addition, the relative contributions of the specific intervention and concurrent exercise training are not easily separable.

Creatine monohydrate is a commonly available nutritional supplement widely used by healthy individuals as an aid to exercise performance. In skeletal muscle, creatine undergoes rapid and reversible phosphorylation, catalysed by the enzyme creatine kinase, to form phosphocreatine (PCr). PCr provides an immediate source of high energy phosphate which is crucial for maintaining the rate of ATP resynthesis during the initial stages of exercise, especially when metabolic demands are high. Uptake and incorporation of exogenous creatine into skeletal muscle is evident in increased resting intramuscular PCr levels. ${ }^{78}$ A large number of studies have looked at creatine supplementation in groups ranging from young athletes to elderly sedentary persons. While results have been variable, the general conclusion of two recent meta-analyses has been that creatine does enhance performance..$^{10}$

There have been few studies of creatine supplementation in disease states, particularly those characterised by impaired exercise tolerance secondary to systemic dysfunction. Muscle performance has been reported to be improved following creatine administration in chronic heart failure, ${ }^{11}$ in mitochondrial myopathies, ${ }^{12}$ and following rehabilitation from disuse atrophy; ${ }^{13}$ however, no evaluations of creatine supplementation in patients with COPD have been published.

Using a randomised, double blind, placebo controlled design, the objective of the present investigation was to evaluate comprehensively the effects on disease status and functional capacity of oral creatine supplementation in patients with moderate to severe COPD, administered firstly in isolation and then in combination with an exercise based pulmonary rehabilitation programme.

\section{METHODS \\ Subjects}

Forty one patients with moderate to severe COPD referred and accepted for pulmonary rehabilitation were recruited and randomised. Two severely impaired patients were unable to complete the exercise evaluations and one additional patient was diagnosed with anaemia, so 38 patients were enrolled in

\footnotetext{
Abbreviations: $\mathrm{BMI}$, body mass index; CWR, constant work rate exercise test; ESWT, endurance shuttle walk test; $F V_{1}$, forced expiratory volume in 1 second; FFM, fat-free mass, FM, fat mass; FVC, forced vital capacity; IET, incremental exercise test; ISWT, incremental shuttle walk test; MIP, maximum inspiratory pressure; MVV, maximum voluntary ventilation; $\mathrm{PCr}$, phosphocreatine; $\mathrm{RPE}$, rating of perceived exertion; SGRQ, St George's Respiratory Questionnaire; TLCO, carbon monoxide transfer factor; $\mathrm{VO}_{2}$, peak oxygen uptake
} 


\begin{tabular}{|c|c|c|}
\hline & $\begin{array}{l}\text { Creatine } \\
\text { ( } \mathrm{n}=18,10 \text { male) }\end{array}$ & $\begin{array}{l}\text { Placebo } \\
\text { ( } n=20,13 \text { male) }\end{array}$ \\
\hline Age (years) & $61.7(8)$ & $63.7(9.7)$ \\
\hline Cigarette (pack years) & $52(32)$ & $52(30)$ \\
\hline \multicolumn{3}{|l|}{ Pulmonary function } \\
\hline $\mathrm{FEV}_{1}(\mathrm{l})$ & $1.12(0.3)$ & $1.13(0.5)$ \\
\hline $\mathrm{FEV}_{1}$ (\% predicted) & $45.4(14)$ & $45.4(16)$ \\
\hline $\mathrm{FEV}_{1} / \mathrm{FVC}$ & $35.9(10.6)$ & $40.9(9.5)$ \\
\hline TLCO (\% predicted) & $46.4(23)$ & $46.6(25)$ \\
\hline $\operatorname{MIP}\left(\mathrm{cm} \mathrm{H} \mathrm{H}_{2} \mathrm{O}\right)$ & $62.3(25)$ & $61.1(29.1)$ \\
\hline \multicolumn{3}{|l|}{ Body composition } \\
\hline Total BM (kg) & $61.9(10.4)$ & $65.5(21.5)$ \\
\hline FFM $(\mathrm{kg})$ & $43.3(8.9)$ & $42.2(12.6)$ \\
\hline FM (kg) & $18.6(8.2)$ & $23.3(11.7)$ \\
\hline $\operatorname{BMI}\left(\mathrm{kg} / \mathrm{m}^{2}\right)$ & $23.2(3.6)$ & $24.3(6.6)$ \\
\hline \multicolumn{3}{|l|}{ Upper limb muscle function } \\
\hline Peak force (N) & $26.7(8.2)$ & $25.6(10.3)$ \\
\hline Total repetitions & $48.9(14.5)$ & $50.6(17.8)$ \\
\hline \multicolumn{3}{|l|}{ Lower limb muscle function } \\
\hline Peak torque (N.m) & $85.7(26.6)$ & $82.2(34.5)$ \\
\hline Total work (J) & $1833(740)$ & $1648(881)$ \\
\hline \multicolumn{3}{|l|}{ Exercise capacity } \\
\hline Peak work rate (W) & $59.0(26.3)$ & $56.0(29.0)$ \\
\hline Peak $\mathrm{VO}_{2}$ (IET, I/min) & $0.85(0.39)$ & $0.86(0.37)$ \\
\hline Lactate threshold (IET, I/min) & $0.55(0.17)$ & $0.53(0.24)$ \\
\hline Breathing reserve (IET, I/min) & $3.3(8.2)$ & $8.2(12.4)$ \\
\hline Peak dyspnoea (IET) & $6.7(1.9)$ & $6.6(1.7)$ \\
\hline Peak RPE (IET) & $7.0(2.2)$ & $6.9(2.0)$ \\
\hline Exercise time (CWR, s) & $164(66)$ & $126(44)$ \\
\hline End-ex dyspnoea (CWR) & $7.8(1.9)$ & $6.5(2.2)$ \\
\hline End-ex RPE (CWR) & $6.3(2.7)$ & $7.3(2.0)$ \\
\hline Distance walked (ISWT, m) & 331 (111) & $293(142)$ \\
\hline Time walked (ESWT, s) & 340 (209) & $392(297)$ \\
\hline \multicolumn{3}{|l|}{ SGRQ } \\
\hline Total score & $65.6(14.0)$ & $67.9(11.4)$ \\
\hline Activity domain & 82.5 (12.9) & $78.8(14.4)$ \\
\hline Impact domain & $50.5(16.3)$ & $56.0(13.0)$ \\
\hline Symptoms domain & $80.4(18.5)$ & $77.1(14.8)$ \\
\hline \multicolumn{3}{|c|}{$\begin{array}{l}\text { Data are presented as group mean (SD) values. } \\
\text { FEV } \text {, forced expiratory volume in } 1 \text { second; FVC, forced vital capacity; } \\
\text { TLCO, carbon monoxide transfer factor; MIP, maximum inspiratory } \\
\text { pressure; BMI, body mass index; BM, body mass; FFM, fat-free mass; } \\
\text { FM, fat mass; } V_{2} \text {, peak oxygen uptake; IET, incremental exercise test; } \\
\text { CWR, constant work rate exercise test; ISWT, incremental shuttle walk } \\
\text { test; ESWT, endurance shuttle walk test; RPE, rating of perceived exertion; } \\
\text { SGRQ, St George's Respiratory Questionnaire. }\end{array}$} \\
\hline
\end{tabular}

the study (table 1). All were clinically stable (no change in medication, no oral corticosteroids, and no exacerbations in the preceding 4 weeks). Long term oxygen therapy precluded recruitment because of difficulty with oxygen provision during the assessments. The ethics committee of North Glasgow University Hospitals granted ethical approval for this study and all patients gave informed consent.

\section{Procedures}

Patients were randomly assigned to receive creatine with glucose polymer ( $5.7 \mathrm{~g}$ creatine monohydrate, equivalent to $5 \mathrm{~g}$ creatine and $35 \mathrm{~g}$ glucose per dose) or glucose polymer only (40.7 g per dose). Supplements were taken three times daily for 14 days (loading phase), followed by once daily administration for 10 weeks (maintenance phase) during which patients attended pulmonary rehabilitation (see below, fig 1). Both supplements had similar taste, texture, and appearance and were placed in generic containers to ensure double blind administration. Patients gave verbal assurance that they had complied with all instructions. Anticipating that body composition might affect responses to the intervention, patients were stratified by nutritional depletion (body mass index (BMI, body mass/height ${ }^{2}$ ) $\leqslant 21 \mathrm{~kg} / \mathrm{m}^{2}$ and/or fat-free mass (FFM) index (FFM/height ${ }^{2}$ ) $\leqslant 16 \mathrm{~kg} / \mathrm{m}^{2}$ for men or $\leqslant 15 \mathrm{~kg} / \mathrm{m}^{2}$ for women). ${ }^{14}$

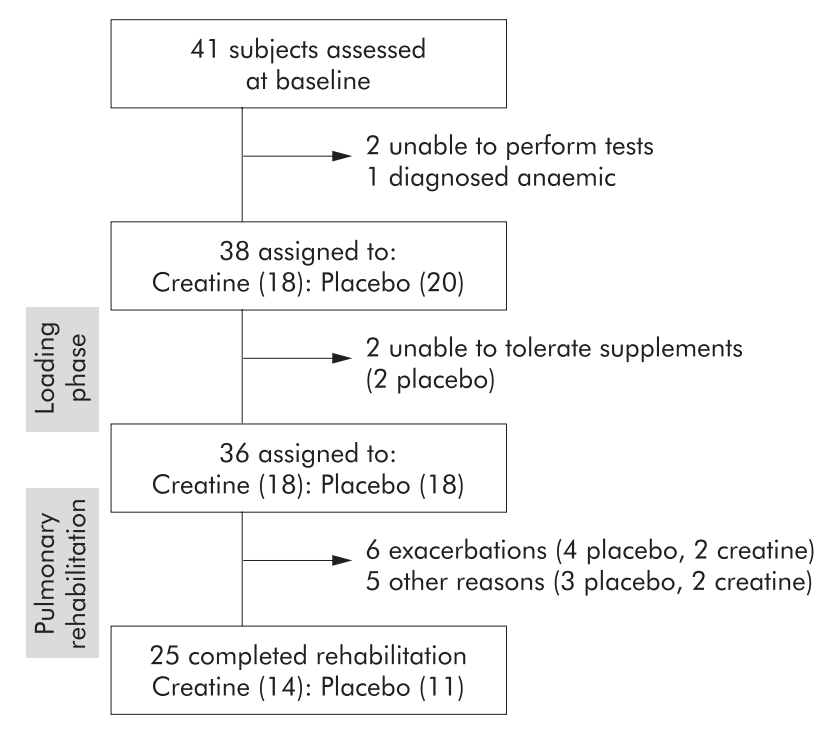

Figure 1 Study plan (see text for further details).

\section{Study protocol}

The study procedures listed below were performed on three occasions-baseline, post loading, and post pulmonary rehabilitation. In order to limit the visits required, the incremental exercise test was not performed after creatine loading. At least 48 hours were allowed between successive tests involving maximal exercise capacity (incremental shuttle walk test, endurance shuttle walk test, incremental cycle ergometry, constant work load cycle ergometry, peripheral muscle strength).

\section{Lung function}

The following measurements were made: spirometric and static lung volumes (V6200 Autobox, SensorMedics Corp, Anaheim, USA); single breath carbon monoxide transfer factor (TLCo; Transflow System, Model 540, Morgan Medical, Kent, UK); maximum inspiratory pressure (MIP; hand held mouth pressure meter, Pearson Medical, North Yorkshire, UK). ${ }^{15}$

\section{Body composition}

Body composition was measured using air displacement plethysmography (ADP) which has been validated for use in COPD. ${ }^{16}$ The uncorrected body volume $\left(\mathrm{Vb}_{\text {uncorr }}\right)$ was measured over a 50 second period. A minimum of two tests were conducted. When two consecutive measurements of $\mathrm{Vb}_{\text {uncorr }}$ were within $0.2 \%$ or $150 \mathrm{ml}$ (whichever was the larger), the results were taken as final and averaged. The corrected body volume was calculated ${ }^{17}$ and fat-free mass (FFM) expressed as \% body mass was estimated from Siri's equation. ${ }^{18}$

\section{Peripheral muscle function}

Lower limb muscle performance was measured using a KinCom II isokinetic dynamometer (Chattecx Corporation, Chattanooga, USA). Each patient's position on the dynamometer was standardised with settings retained for subsequent tests. Quadriceps muscle strength was measured as the isokinetic peak torque. Patients were instructed to exert maximal effort throughout the full range of motion during each repetition. Five consecutive maximal isokinetic concentric contractions were performed at a speed of $70 \% \mathrm{~s}$ with a 30 second rest period between repetitions. After a 5 minute recovery period, quadriceps muscle endurance was measured as the cumulative work over five sets of 15 repetitions at a 
speed of $150 \%$ s. Patients were given a 2 minute rest period between sets. ${ }^{8}$

Following a further 10 minute rest, upper limb strength and endurance were measured on the dominant and nondominant hands using a handgrip dynamometer (Grip-A, Takei Scientific Instruments Co, Niigta, Japan). Handgrip strength was measured from five consecutive maximal voluntary isometric contractions with a 30 second rest between each contraction. Handgrip endurance was then measured as the number of contractions that a patient could complete to the point of fatigue in each of three consecutive sets, with a 2 minute rest between each set; intensity was set at $70 \%$ of the individual predetermined one repetition maximum. Fatigue was defined as the failure to exert the required intensity for three consecutive contractions. The same investigator conducted all tests.

\section{Whole body exercise capacity}

Incremental and endurance shuttle walk tests (ISWT and ESWT, respectively) were performed using standard proto$\operatorname{cols}^{1920}$ including a practice ISWT at initial assessment. Symptom limited rapid incremental exercise tests (IET; work rate incrementation rate $5-10$ Watts/min) were performed on a cycle ergometer (Corival 400, Lode, Groningen, The Netherlands) only at baseline and after rehabilitation. Symptom limited constant work rate cycle ergometer exercise tests (CWR) were performed at $80 \%$ of peak work rate (determined from the baseline IET). Pulmonary gas exchange variables were monitored breath-by-breath. Peak oxygen uptake $\left(\mathrm{VO}_{2}\right.$ peak) was measured as the mean $\mathrm{Vo}_{2}$ for the last 15 seconds of the IET. The lactate threshold was estimated from expired gas analysis when there was hyperventilation relative to oxygen but not carbon dioxide. ${ }^{21}$ Maximum voluntary ventilation $(\mathrm{MVV})$ was defined as $40 \times \mathrm{FEV}_{1}{ }^{22}$ Breathing reserve was calculated as the difference between the predicted MVV and the maximum ventilation over the last 15 seconds of the incremental exercise test. Ratings of perceived exertion and breathlessness were obtained (modified Borg scale $)^{23}$ at rest, at the limit of tolerance, and at 2 and 5 minutes recovery.
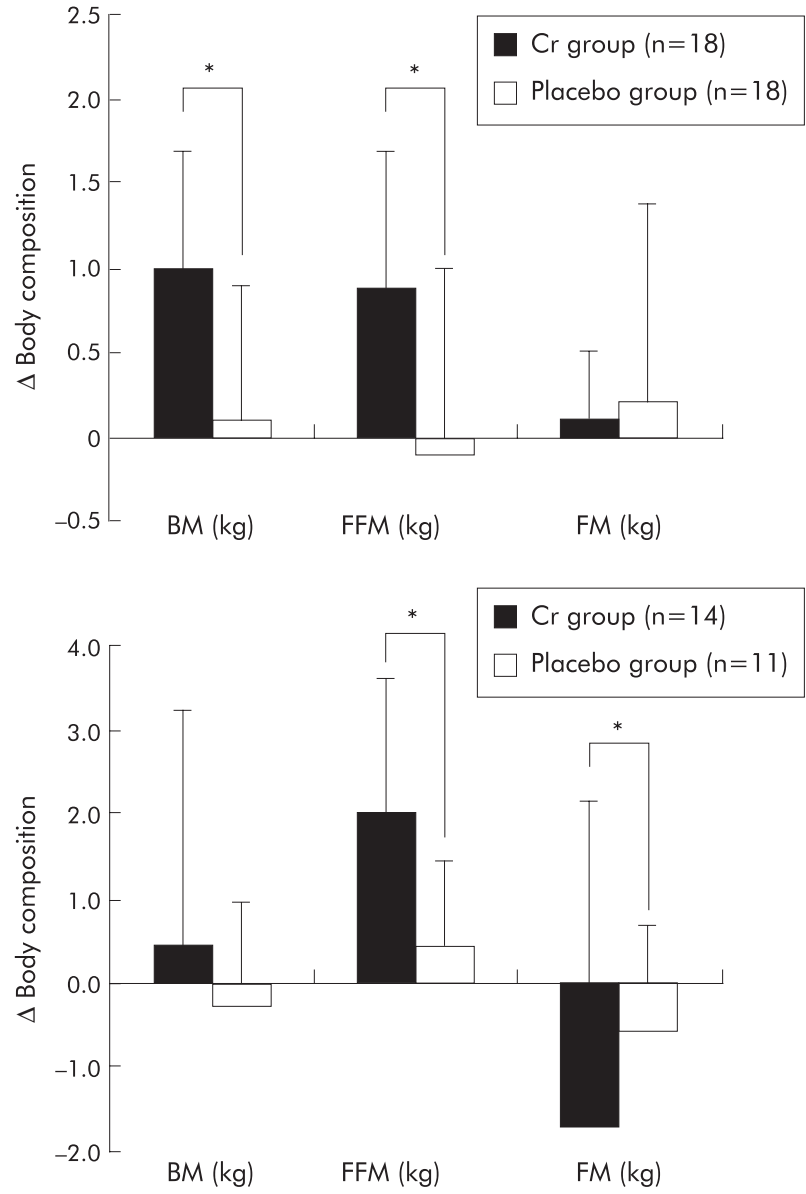

Figure 2 Group mean (SD) responses of body mass (BM), fat-free mass (FFM), and fat mass (FM) to the initial loading phase (upper panel) and the subsequent training phase with supplementation maintained (lower panel) for the creatine group (solid bars) and the placebo group (open bars). Responses are expressed as absolute changes from baseline $(\Delta)_{i}$ bars represent $\pm 1 S D$.

Table 2 Responses to initial loading phase for creatine and placebo groups

\begin{tabular}{|c|c|c|c|}
\hline & $\begin{array}{l}\text { Creatine } \\
(n=18)\end{array}$ & $\begin{array}{l}\text { Placebo } \\
(n=18)\end{array}$ & Creatine versus placebo difference \\
\hline \multicolumn{4}{|l|}{ Pulmonary function } \\
\hline $\mathrm{FEV}_{1}$ (I) & $-0.01(-0.1$ to 0.1$)$ & $-0.05(-1.79$ to 0.07$)$ & $0.05(-0.11$ to 0.19$)$ \\
\hline $\operatorname{MIP}\left(\mathrm{cm} \mathrm{H}_{2} \mathrm{O}\right)$ & $7.13(-0.3$ to 14.5$)$ & $3.69(-2.2$ to 9.6$)$ & $3.44(-5.62$ to 12.49$)$ \\
\hline \multicolumn{4}{|l|}{ Body composition } \\
\hline Total BM $(\mathrm{kg})$ & $1.1(0.7$ to 1.4$) \S \S$ & $0.1(-0.3$ to 0.5$)$ & $0.95(0.43 \text { to } 1.8)^{*}$ \\
\hline FFM $(\mathrm{kg})$ & $0.9(0.6$ to 1.3$) \S \S$ & $-0.2(-0.7$ to 0.4$)$ & $1.09(0.43 \text { to } 1.74)^{*}$ \\
\hline $\mathrm{FM}(\mathrm{kg})$ & $0.1(-0.1$ to 0.3$)$ & $0.2(-0.3$ to 0.8$)$ & $-0.13(-0.71$ to 0.44$)$ \\
\hline \multicolumn{4}{|l|}{ Upper limb muscle function } \\
\hline Peak force (N) & $0.6(-1.4$ to 2.6$)$ & $-0.12(-1.92$ to 1.68$)$ & $0.72(-0.58$ to 2.02$)$ \\
\hline Total repetitions & $3.9(1.9$ to 6$) \S \S$ & $1.1(-2.4$ to 4.6$)$ & $2.89(0.26 \text { to } 5.52)^{*}$ \\
\hline \multicolumn{4}{|l|}{ Lower limb muscle function } \\
\hline Peak torque (N.m) & $3.5(2.3$ to 4.7$) \S \S$ & $-0.7(-3.4$ to 2.0$)$ & $4.2(1.4 \text { to } 7.1)^{*}$ \\
\hline Total work (J) & $424(137$ to 710$) \S \S$ & $13(-44$ to 69$)$ & $411.1(129.9 \text { to } 692.4)^{* *}$ \\
\hline \multicolumn{4}{|l|}{ Exercise capacity } \\
\hline Time to intolerance (CWR, s) & $15(-30$ to 60$)$ & $54(18$ to 90$) \S$ & $-40.0(-94.3$ to 16.3$)$ \\
\hline End-ex dyspnoea (CWR) & $-0.3(-1.9$ to 1.3$)$ & $0.2(-0.7$ to 1.1$)$ & $-0.5(-2.0$ to 1.0$)$ \\
\hline End-ex RPE (CWR) & $0.2(-1$ to 1.4$)$ & $-1.0(-2$ to 0.0$)$ & $1.3(0.4$ to 2.9$)$ \\
\hline Distance walked (ISWT, m) & $-8(-44$ to 28$)$ & $15(-19$ to 50$)$ & $-23.1(-71.7$ to 25.5$)$ \\
\hline Time walked (ESWT, s) & $132(61$ to 203$) \S \S$ & $92(-59$ to 242$)$ & $40.5(-115.7$ to 196.7$)$ \\
\hline
\end{tabular}

Data are presented as group mean values (with $95 \%$ confidence intervals) for the absolute changes from baseline and between group difference. $\mathrm{FEV}$, forced expiratory volume in 1 second; MIP, maximum inspiratory pressure; BM, body mass; FFM, fat-free mass, FM, fat mass; IET, incremental exercise test; CWR, constant work rate exercise test; ISWT, incremental shuttle walk test; ESWT, endurance shuttle walk test; RPE, rating of perceived exertion. Statistically significant differences: $\S p<0.05, \S \S p<0.01$ (within-group difference from baseline); ${ }^{*} p<0.05,{ }^{* *} p<0.01$ (between-group differences). 
Health status

Health related quality of life was evaluated at study entry and after pulmonary rehabilitation using the St George's Respiratory questionnaire (SGRQ). ${ }^{24}$

\section{Pulmonary rehabilitation}

Patients participated in the hospital pulmonary rehabilitation programme. The programme consisted of 16 twice weekly sessions, each 1 hour long. Each session consisted of a warm-up, mobility training, dynamic strength training of the upper and lower extremities through circuit based stations, whole body endurance training (20 minutes cycle ergometry), and stretching exercise. Training intensity was individualised according to the associated Borg dyspnoea ratings, set at $1-2$ units below maximum achieved on the ISWT. Patients were also given a copy of alternative exercises for additional home based training. In addition, there was a non-exercise component focusing on education and behavioural interventions delivered by a multidisciplinary team including nurses, physiotherapists, occupational therapists, dieticians, and doctors. There was no formal psychological input.

\section{Statistical analysis}

The primary outcome measure of this trial was distance walked on the ISWT. The study was powered to detect equivalent effects to those reported for pulmonary rehabilitation (mean (SD) improvement of 56 (58) metres on ISWT recalculated from Singh et $\left.a l^{25}\right)$. We aimed to recruit 60 patients with an expected 33\% drop out over the rehabilitation period. After investigation of data normality, values were expressed as mean values with $95 \%$ confidence intervals (CI). Statistical analysis was carried out using paired (withintreatment effect) and unpaired (between-treatment effect) $t$ tests. Statistical significance was set at $\mathrm{p}<0.05$. Pearson correlation analysis was used to assess relationships between variables.

\section{RESULTS}

We were unable to recruit the number of patients originally planned because of financial and timing restraints.

\section{Baseline evaluation}

Anthropometric and functional baseline characteristics of the 38 patients enrolled in the study are presented in table 1 . There were no significant differences in baseline characteristics between the placebo $(n=20)$ and creatine $(n=18)$ groups, including FFM depletion (10 in the placebo group, nine in the creatine group).

\section{Post-loading evaluation}

The supplementation was generally well tolerated without reported side effects. Two patients from the placebo group did not complete the loading phase because of a dislike of the sweet taste (fig 1). The results of 36 subjects are therefore reported and are summarised in table 2 .

\section{Whole body exercise capacity}

There was no improvement in the primary end point of ISWT, with no change in distance walked compared with baseline in either group. There were within group changes but no significant between group differences for other measures (table 2). ESWT improved significantly with creatine (132 s or $38.8 \%$; $\mathrm{p}<0.01$ ), but this did not differ from a nonsignificant improvement seen with placebo (92 s or $23.5 \%$; $\mathrm{p}=0.21)$. The CWR showed a non-significant change in exercise time for creatine (15 s or $9.1 \%$; $p=0.49$ ) but,

\begin{tabular}{|c|c|c|c|}
\hline & $\begin{array}{l}\text { Creatine } \\
(n=14)\end{array}$ & $\begin{array}{l}\text { Placebo } \\
(n=11)\end{array}$ & Creatine versus placebo difference \\
\hline \multicolumn{4}{|l|}{ Pulmonary function } \\
\hline $\mathrm{FEV}_{1}$ (I) & $-0.036(-0.1$ to 0.07$)$ & $-0.06(-0.8$ to 0.06$)$ & $0.02(-0.13$ to 0.18$)$ \\
\hline MIP $\left(\mathrm{cm} \mathrm{H}_{2} \mathrm{O}\right)$ & $1.15(-8.1$ to 3.9$)$ & $-0.27(-11.6$ to 6.3$)$ & $1.43(-8.8$ to 11.7$)$ \\
\hline \multicolumn{4}{|l|}{ Body composition } \\
\hline Total BM $(\mathrm{kg})$ & $0.4(-1.3$ to 2.0$)$ & $-0.3(-0.9$ to 0.4$)$ & $0.66(-1.19$ to 2.52$)$ \\
\hline FFM $(\mathrm{kg})$ & $2.0(1.1$ to 3.0$) \S \S$ & $0.4(-0.2$ to 1.0$)$ & $1.62(0.47 \text { to } 2.77)^{*}$ \\
\hline FM (kg) & $-1.7(-2.9$ to -0.4$)$ & $-0.6(-1.0$ to -0.1$)$ & $-1.10(-2.47$ to 0.28$)$ \\
\hline \multicolumn{4}{|l|}{ Upper body muscle function } \\
\hline Peak force (dominant), N & $2.9(0.3$ to 5.5$) \S$ & $0.6(-1.1$ to 2.3$)$ & $2.27(0.33 \text { to } 4.21)^{*}$ \\
\hline Total repetitions (dominant) & $15.6(8.4$ to 22.8$) \S \S$ & $8.4(3.9$ to 12.9$) \S$ & $7.28(2.16 \text { to } 12.40)^{*}$ \\
\hline \multicolumn{4}{|l|}{ Lower body muscle function } \\
\hline Peak torque (N.m) & 19.5 (14.9 to 23.3$) \S \S$ & $12.2(4.4$ to 14.4$) \S$ & $7.30(0.69 \text { to } 13.92)^{*}$ \\
\hline Total work (J) & $1216(634$ to 1798$) \S \S$ & $362(48$ to 710$) \S \S$ & $854.3(131.3 \text { to } 1577.4)^{*}$ \\
\hline \multicolumn{4}{|l|}{ Exercise capacity } \\
\hline Peak work rate (W) & $-0.71(-13.2$ to 11.8$)$ & $-5.0(-14.0$ to 4.0$)$ & $4.29(-12.5$ to 21.1$)$ \\
\hline Peak $\mathrm{VO}_{2}$ (IET, $\left.\mathrm{I} / \mathrm{min}\right)$ & $0.061(-0.06$ to 0.20$)$ & $-0.074(-0.2$ to 0.02$)$ & $0.14(-0.02$ to 0.29$)$ \\
\hline Lactate threshold (IET, I/min) & $0.11(0.03$ to 0.19$) \S$ & $0.04(-0.07$ to 0.15$)$ & $0.07(-0.07$ to 0.21$)$ \\
\hline End-ex dyspnoea (IET) & $-0.69(-1.94$ to 0.55$)$ & $0.00(-1.44$ to 1.44$)$ & $-0.69(-2.44$ to 1.05$)$ \\
\hline End-ex RPE (IET) & $-1.15(-2.84$ to 0.54$)$ & $0.00(-1.38$ to 1.38$)$ & $-1.15(-3.30$ to 0.99$)$ \\
\hline Exercise time (CWR, s) & $214(20$ to 409$) \S$ & $243(-1$ to 488$)$ & $-29.0(-317.8$ to 259.8$)$ \\
\hline End-ex dyspnoea (CWR) & $-1.3(-2.3$ to -0.3$) \S$ & $-0.4(-1.4$ to 0.6$)$ & $0.9(-2.4$ to 0.6$)$ \\
\hline End-ex RPE (CWR) & $-1.1(-2.4$ to 0.2$)$ & $-0.4(-1.7$ to 0.9$)$ & $0.7(-2.7$ to 1.2$)$ \\
\hline Distance walked (ISWT, m) & $55(5$ to 104$) \S$ & $76(21$ tol31)§ & $-21.5(-90.6$ to 47.7$)$ \\
\hline Time walked (ESWT, s) & 365 (181 to 550$) \S \S$ & $275(90$ to 460$) \S \S$ & $90.5(-157.6$ to 339$)$ \\
\hline \multicolumn{4}{|l|}{ SGRQ } \\
\hline Total score & $-5.9(-1.1$ to -10.8$) \S$ & $1.8(-4.1$ to 7.7$)$ & $-7.7(-14.9 \text { to }-0.5)^{\star}$ \\
\hline Activity domain & $-5.3(-1.7$ to -8.9$) \S \S$ & $11.0(1.8$ to 20.1$) \S$ & $-16.3(-24.8 \text { to }-7.9)^{* *}$ \\
\hline Impact domain & $-3.46(-10.2$ to 3.3$)$ & $-3.45(-10.3$ to 3.4$)$ & $-0.01(-9.2$ to 9.2$)$ \\
\hline Symptoms domain & $-4.3(-15.1$ to 6.4$)$ & $0.2(-10.0$ to 10.5$)$ & $-4.5(-18.9$ to 9.8$)$ \\
\hline
\end{tabular}

Data are presented as group mean values (with $95 \%$ confidence intervals) for the absolute changes from baseline and between-group difference. $\mathrm{FEV}_{1}$, forced expiratory volume in 1 second; MIP, maximum inspiratory pressure; BM, body mass; FFM, fat-free mass, FM, fat mass; IET, incremental exercise test; CWR, constant work rate exercise test; ISWT, incremental shuttle walk test; ESWT, endurance shuttle walk test; RPE, rating of perceived exertion. Statistically significant differences: $\S p<0.05, \S \S p<0.01$ (within-group difference from baseline); ${ }^{*} p<0.05$, ** $p<0.01$ (between-group differences). 
surprisingly, an increase for placebo (54 s or $42.8 \%$; $<<0.05$ ), between-group difference $(\mathrm{p}=0.17)$.

\section{Muscle function}

Creatine loading resulted in increases in several muscle performance measures from the pre-intervention baseline. In contrast with whole body exercise testing, these changes were significant compared with placebo: lower limb strength compared with placebo (3.5 N.m or $4.1 \% v-0.7$ N.m or $-0.9 \% ; \mathrm{p}<0.05$ ); lower limb endurance (424 J or $23.1 \% v$ $13 \mathrm{~J}$ or $0.8 \% ; \mathrm{p}<0.01)$. Handgrip endurance increased significantly relative to placebo (3.9 repetitions or $8.0 \% \mathrm{v}$ 1.1 repetitions or $2.2 \% ; \mathrm{p}<0.05)$. Peak handgrip force was unaffected in either group.

\section{Body composition}

Body weight increased with creatine relative to placebo (1.1 kg or $1.8 \% v 0.1 \mathrm{~kg}$ or $0.2 \% ; \mathrm{p}<0.05$ ), predominantly in the FFM component $(0.9 \mathrm{~kg}$ or $1.3 \% v-0.2 \mathrm{~kg}$ or $0.5 \%$; $\mathrm{p}<0.05$; fig 2).

\section{Post-rehabilitation evaluation}

Twenty five patients successfully completed the exercise based rehabilitation programme (fig 1). The reasons for study discontinuation were severe exacerbations (2 creatine; 4 placebo), poor motivation or non-compliance with the exercise programme (1 creatine; 2 placebo), backache (1 creatine), and vestibular disease ( 1 placebo). Changes seen in response to exercise training are calculated from baseline entry into the study for both groups. The effects of the exercise training itself are indicated by responses of the placebo group. The results are summarised in table 3.

\section{Whole body exercise testing}

The placebo group showed significant improvement in ISWT ( $76 \mathrm{~m}$ or $25.9 \%$; $\mathrm{p}<0.05)$ and ESWT $(275 \mathrm{~s}$ or $70.1 \%$; $\mathrm{p}<0.01)$. Breathlessness and perceived exertion at endexercise on the CWR test were unaffected, as was $V_{\mathrm{O}_{2}}$ peak and the lactate threshold on the IET. Creatine supplementation combined with rehabilitation provided no further statistically significant improvement in whole body exercise capacity (shuttle walks, cycle ergometry) compared with rehabilitation alone (placebo). Although the lactate threshold increased from baseline with creatine $(0.11 \mathrm{l} / \mathrm{min}$ or $20 \% ; \mathrm{p}<0.05)$, this was not significant compared with placebo. There was a significant decline in breathlessness with creatine at end-exercise for the CWR test compared with baseline $(-1.3$ or $-16.7 \%$; $\mathrm{p}<0.05)$.

\section{Muscle function}

After rehabilitation with placebo, lower limb strength and endurance increased relative to baseline. Handgrip endurance also increased although strength was unaffected. The gains in muscle performance with training were significantly enhanced with creatine compared with placebo: lower limb strength (19.5 N.m or $22.8 \% v 12.2$ N.m or $14.8 \%$; $<<0.05$ ) and endurance (1216 J or $66 \% \vee 362 \mathrm{~J}$ or $22.0 \%$; $<<0.05$ ), handgrip strength $(2.9 \mathrm{~N}$ or $10.9 \% v 0.6 \mathrm{~N}$ or $2.3 \%$; $<<0.05)$ and endurance ( 15.6 or $31.9 \% \vee 8.4$ or $16.6 \%$; $<<0.05$ ).

\section{Body composition}

Fat-free mass following combined rehabilitation and creatine was substantially greater than for rehabilitation alone $(2.0 \mathrm{~kg}$ or $2.8 \% v 0.4 \mathrm{~kg}$ or $0.6 \%$; $\mathrm{p}<0.05$, fig 2 ).

\section{Quality of life}

Improvement in quality of life (SGRQ total and activity domain scores) was enhanced by combined creatine supplementation and rehabilitation: SGRQ total score decreased by
5.9 or $9.0 \%$ compared with an increase of 1.8 or $2.7 \%$ for placebo $(\mathrm{p}<0.05)$ and SGRQ activity domain score decreased by 5.3 or $6.4 \%$ compared with an increase of 11.0 or $14 \%$ for placebo $(\mathrm{p}<0.01)$. The worsening of the activity domain for the placebo group over the study duration is surprising.

No significant relationships were found between baseline functional indices (that is, pulmonary function, body composition, exercise tolerance) and any subsequent benefit from creatine supplementation, without or with pulmonary rehabilitation. For instance, there was no correlation between change in FFM and muscle strength $(r=0.08, \mathrm{p}=0.8$ post loading and $r=0.24, \mathrm{p}=0.4$ post rehabilitation).

The improvements seen after rehabilitation in both exercise capacity and health related quality of life represent clinically meaningful improvements. The ISWT increased by over $50 \mathrm{~m}$ in both creatine and placebo groups, with six patients in each group exceeding this value. ${ }^{26}$ The SGRQ total score decreased by more than 4 points in the creatine group, with six patients in this group exceeding this value compared with one in the placebo group. ${ }^{27}$

\section{DISCUSSION}

We have shown that 2 weeks of oral creatine supplementation (15 g/day) loading increased FFM and upper and lower limb muscle strength and endurance in patients with moderate to severe COPD. Maintenance creatine supplementation $(5 \mathrm{~g} /$ day) potentiated the effects of pulmonary rehabilitation with additional improvements in FFM and upper and lower limb muscle performance and quality of life. However, creatine produced no improvement in whole body exercise performance.

\section{Body mass and FFM}

Consistent with earlier reports in healthy individuals ${ }^{28} 29$ and in patients with heart failure, ${ }^{11}$ the initial 2 week loading phase of creatine supplementation led to an increased (predominantly fat-free) body mass. Maintenance supplementation and rehabilitation were associated with a further increase in FFM (fig 2; tables 2 and 3). Although gain in muscle mass with pulmonary rehabilitation alone has been reported, ${ }^{30}$ our study population differed in including a proportion of underweight individuals and having outpatient rather than residential rehabilitation. The Bod Pod method of body composition uses a two-compartment model for FFM estimation. Although validated for use in COPD, it may be more sensitive to alterations in water content than three-compartment methods. Simple water retention might explain the gain in FFM seen with creatine but could not explain improved muscle function. The mechanism underlying the creatine induced increase in FFM is unclear. Creatine ingestion does cause water retention which is presumed to reflect local gains within skeletal muscle rather than more generalised fluid shifts. ${ }^{31}$ Creatine may stimulate myocyte protein synthesis directly ${ }^{32}$ or indirectly by myocyte swelling. ${ }^{33}$

\section{Muscle strength and endurance}

Creatine loading produced increases in lower limb strength and endurance and handgrip endurance. Further improvements in both lower limb and handgrip strength and endurance were seen with creatine supplementation and rehabilitation (tables 2 and 3). Similar effects with creatine have been reported in healthy younger ${ }^{28}$ and older subjects, ${ }^{29}$ and in those with heart failure ${ }^{16}$ Lower limb muscle strength is more affected than upper limb strength in patients with COPD. ${ }^{34}$ This has been attributed to reduced locomotor muscle use and consequent detraining. Creatine is reported to have a greater effect on muscles that are relatively detrained. ${ }^{13}$ Consistent with this, gains in lower limb strength 
and endurance were proportionately greater than for the upper limb.

The mechanisms responsible for these observed creatine induced increases in muscle strength and endurance are uncertain. Loading regimes ranging in duration from 2 to 7 days with $20-25 \mathrm{~g} /$ day creatine have produced changes in muscle total creatine of $6-35 \mathrm{mmol} / \mathrm{kg}$ dry matter. ${ }^{7}$ Peripheral muscle abnormalities in COPD include low resting ATP and $\mathrm{PCr}$ concentrations, ${ }^{35}$ lower intracellular $\mathrm{pH}$ and slower $\mathrm{PCr}$ resynthesis during recovery from exercise. ${ }^{36}$ Both an increase in resting PCr levels and an accelerated rate of post-exercise $\mathrm{PCr}$ resynthesis may explain the effect of creatine supplementation. ${ }^{8}$

The creatine group gained more benefit from the rehabilitation programme with respect to muscle performance (lower limb and handgrip strength and endurance). Creatine supplementation may have permitted training at a greater intensity resulting in improved muscle performance. We did not document each individual's training so do not have evidence for this hypothesis. Enhanced muscle performance by combining creatine and exercise training has been reported in healthy subjects ${ }^{11}$ but not in patient groups.

\section{Whole body exercise performance}

The effects of creatine supplementation on whole body exercise performance in healthy subjects are generally acknowledged to be more variable. The consensus is that high intensity sprint exercise can be improved, but graded exercise and constant work rate tests (less reliant on PCr) are less consistently altered..$^{90}$ In this context, the failure of creatine to improve shuttle walking and symptom limited cycle ergometry is not entirely surprising. There were no between-group improvements in exercise tolerance as measured by walking or cycle ergometry tests, nor in peak $\mathrm{VO}_{2}$ or the lactate threshold. The fact that the improvements in body composition and muscle function with creatine did not translate into improved exercise performance may relate to the tests performed and the multifactorial nature of exercise intolerance in patients with COPD.

Training itself induced some performance gains for whole body exercise, notably for shuttle walking, as expected. ${ }^{37}$ The lack of effect on peak $\mathrm{VO}_{2}$ and lactate threshold is not without precedent, especially in patients who are substantially impaired in terms of respiratory limitation. ${ }^{38}$ There was considerable variability in the changes seen in exercise endurance time following intervention. Such tests are known to be susceptible to learning effects, ${ }^{39}$ especially in COPD. ${ }^{40}$ We were, however, unable to incorporate additional familiarisation sessions into our protocol.

\section{Quality of life}

We found clinically meaningful improvements in health related quality of life with creatine and rehabilitation compared with rehabilitation alone. The lack of effect on quality of life in the placebo group was unexpected. We used the standard hospital rehabilitation programme that met the minimum standards set by the British Thoracic Society; this may not be the equivalent of research orientated programmes whose outcomes have set the expected standard. Nonetheless, the placebo group showed improvement in exercise capacity which shows that our programme was effective. The role of other factors such as exacerbation frequency is unknown as we did not record such data. We speculate that creatine improved muscle function with a beneficial impact on activities of daily living reflected in the improved activity domain of the SGRQ, despite lack of significant improvements in whole body exercise capacity.

\section{Study limitations}

We failed to recruit the 60 patients planned due to time and funding constraints. It is unlikely that, had we done so, we would have detected an improvement in ISWT as our confidence intervals are wide relative to the magnitude of change. Also, as the study was unable to recruit the number of patients deemed necessary from the power calculation, the 95\% confidence intervals for exercise capacity include a wide range of possible values for the difference between creatine and placebo which this study is unable to rule out.

Our patients come from a socially deprived population who then entered our hospital pulmonary rehabilitation programme. The drop out rates $(39 \%$ for placebo and $22 \%$ for creatine) were unremarkable for our local programme although higher than generally reported in research settings.

We did not assess dietary intake, uptake by repeated muscle biopsy, or urinary excretion of creatine and therefore cannot correlate intake, uptake, or initial deficit of creatine with responses. The design of our study also did not allow us to resolve the relative contributions of creatine supplementation and training on changes in body composition and muscle performance, or if the effects varied with nutritional status. The primary purpose of our study was to explore the effects of creatine alone and with exercise training in a largely unselected patient group.

\section{Conclusions}

This study shows that oral creatine monohydrate supplementation, both in isolation and in combination with pulmonary rehabilitation, improved FFM and skeletal muscle function but not whole body exercise capacity in a group of patients with advanced COPD. In addition, creatine led to benefits in health related quality of life over the course of the study. Creatine did not have any demonstrable beneficial effect on exercise capacity, the primary end point of our investigation. The potential importance of these findings should be considered in the light of the knowledge that peripheral muscle wasting ${ }^{1}$ and body mass are strong and independent predictors of mortality in COPD. To our knowledge, this is the first pharmacological intervention study in COPD to show increased muscle function in association with increased FFM. Previously reported interventions in patients with COPD—such as administration of anabolic steroids, recombinant growth hormone, ${ }^{4}$ appetite stimulants, ${ }^{6}$ and nutritional intervention ${ }^{3}$ - while altering body composition were without effect on peripheral muscle performance. The functional improvements with creatine supplementation alone may be of importance for patients with COPD who may not be able to undertake whole body exercise training sessions either because of advanced disease or co-morbidity. Further studies are required to verify our observations and to assess the impact of creatine supplementation on mortality in COPD. These data suggest that creatine may constitute a novel ergogenic aid for clinical use in patients with COPD.

\section{ACKNOWLEDGEMENTS}

The authors thank Dr Roger Carter (Department of Respiratory Medicine, Glasgow Royal Infirmary) for his assistance with the pulmonary function tests, Heather Collin and Kay Pollock (Institute of Biomedical and Life Sciences, University of Glasgow) for the preparation of the trial supplements, and Tom Fanshawe (Centre for Applied Medical Statistics, University of Cambridge) for statistical advice.

\section{Authors' affiliations}

J P Fuld, L P Kilduff, J A Neder, Y Pitsiladis, S A Ward, Centre for Exercise Science and Medicine, Institute of Biological and Life Sciences, University of Glasgow, Glasgow, UK

J P Fuld, M M Cotton, Department of Respiratory Medicine, Glasgow Royal Infirmary, Glasgow, UK 
L P Kilduff, Department of Sports Science, University of Wales, Swansea, UK

M E J Lean, Department of Human Nutrition, University of Glasgow, Glasgow, UK

S A Ward, School of Sport and Exercise Sciences, University of Leeds, Leeds, UK

JP Fuld was supported in part by the Wellcome Trust, UK

The authors have no conflicts of interest with regard to this manuscript.

\section{REFERENCES}

1 Marquis K, Debigare R, Lacasse Y, et al. Mid thigh muscle cross-sectional area is a better predictor of mortality than body mass index in patients with chronic obstructive pulmonary disease. Am J Respir Crit Care Med 2002; 166:809-13.

2 Schols AM. Nutritional and metabolic modulation in chronic obstructive pulmonary disease management. Eur Respir J Supp/ 2003:46:81-6s.

3 Steiner MC, Barton RL, Singh SJ, et al. Nutritional enhancement of exercise performance in chronic obstructive pulmonary disease: a randomised controlled trial. Thorax 2003;58:745-51.

4 Burdet L, de Muralt B, Schutz Y, et al. Administration of growth hormone to underweight patients with chronic obstructive pulmonary disease. A prospective, randomized, controlled study. Am J Respir Crit Care Med 1997; 156:1800-6.

5 Creutzberg EC, Wouters EF, Mostert R, et al. A role for anabolic steroids in the rehabilitation of patients with COPD? A double-blind, placebo-controlled, randomized trial. Chest 2003;124:1733-42.

6 Weisberg J, Wanger J, Olson J, et al. Megestrol acetate stimulates weight gain and ventilation in underweight COPD patients. Chest 2002;121:1070-8.

7 Harris RC, Soderlund K, Hultman E. Elevation of creatine in resting and exercised muscle of normal subjects by creatine supplementation. Clin $\mathrm{Sci}$ (Lond) 1992:83:367-74

8 Greenhaff PL, Bodin K, Soderlund K, et al. Effect of oral creatine supplementation on skeletal muscle phosphocreatine resynthesis. Am J Physiol 1994;266:E725-30

9 Branch JD. Effect of creatine supplementation on body composition and performance: a meta-analysis. Int J Sport Nutr Exerc Metab 2003; 13:198-226.

10 Nissen SL, Sharp RL. Effect of dietary supplements on lean mass and strength gains with resistance exercise: a meta-analysis. J Appl Physiol 2003:94:651-9.

11 Andrews R, Greenhaff P, Curtis S, et al. The effect of dietary creatine supplementation on skeletal muscle metabolism in congestive heart failure. Eur Heart J 1998;19:617-22.

12 Tarnopolsky MA, Roy BD, MacDonald JR. A randomized, controlled trial of creatine monohydrate in patients with mitochondrial cytopathies. Muscle Nerve 1997;20:1502-9.

13 Hespel $P, O p^{\prime}+E B$, van Leemputte $M$, et al. Oral creatine supplementation facilitates the rehabilitation of disuse atrophy and alters the expression of muscle myogenic factors in humans. J Physiol 2001;536:625-33.

14 Vanltallie TB, Yang MU, Heymsfield SB, et al. Height-normalized indices of the body's fat-free mass and fat mass: potentially useful indicators of nutritional status. Am J Clin Nutr 1990;52:953-9.

15 Polkey MI, Green M, Moxham J. Measurement of respiratory muscle strength Thorax 1995:50:1131-5.

16 Kilduff LP, Neder JA, Fuld JP, et al. Limits of agreement between different methods of fat-free mass estimation and their clinical significance in patients with COPD. Respiration 2003;70:585-93.
17 Dempster P, Aitkens S. A new air displacement method for the determination of human body composition. Med Sci Sports Exerc 1995;27:1692-7.

18 Siri WE. Body composition from fluid spaces and density: analysis of methods. Washington, DC: Techniques for Measuring Body Composition, 1961:223-4.

19 Singh SJ, Morgan MD, Scott S, et al. Development of a shuttle walking test of disability in patients with chronic airways obstruction. Thorax 1992;47:1019-24.

20 Revill SM, Morgan MD, Singh SJ, et al. The endurance shuttle walk: a new field test for the assessment of endurance capacity in chronic obstructive pulmonary disease. Thorax 1999;54:213-22.

21 Whipp BJ, Ward SA, Wasserman K. Respiratory markers of the anaerobic threshold. Advan Cardiol 1986;35:47-64.

22 Hansen JE, Sue DY, Wasserman K. Predicted values for clinical exercise testing. Am Rev Respir Dis 1984;129:S49-55.

23 Borg GAV. Psychophysical basis of percieved exertion. Med Sci Sports Exerc 1982;14:377-81.

24 Jones PW, Quirk FH, Baveystock CM, et al. A self-complete measure of health status for chronic airflow limitation. The St George's Respiratory Questionnaire. Am Rev Respir Dis 1992;145:1321-7.

25 Singh SJ, Smith DL, Hyland ME, et al. A short outpatient pulmonary rehabilitation programme: immediate and longer-term effects on exercise performance and quality of life. Respir Med 1998;92:1146-54.

26 British Thoracic Society. Pulmonary rehabilitation Thorax 2001;56:827-34

27 Jones PW, Quirk FH, Baveystock CM. The St George's Respiratory Questionnaire. Respir Med 1991;85(Suppl B):25-31.

28 Kilduff LP, Vidakovic P, Cooney G, et al. Effects of creatine on isometric bench-press performance in resistance- trained humans. Med Sci Sports Exerc 2002;34:1176-83

29 Gotshalk LA, Volek JS, Staron RS, et al. Creatine supplementation improves muscular performance in older men. Med Sci Sports Exerc 2002;34:537-43.

30 Franssen FM, Broekhuizen R, Janssen PP, et al. Effects of whole-body exercise training on body composition and functional capacity in normal-weight patients with COPD. Chest 2004; 125:2021-8.

31 Hultman E, Soderlund K, Timmons JA, et al. Muscle creatine loading in men. J Appl Physiol 1996;81:232-7.

32 Ingwall JS, Weiner CD, Morales MF, et al. Specificity of creatine in the control of muscle protein synthesis. J Cell Biol 1974;62:145-51.

33 Haussinger $D$, Roth $E$, Lang $F$, et al. Cellular hydration state: an important determinant of protein catabolism in health and disease. Lancet 1993:341:1330-2.

34 Gosselink R, Troosters T, Decramer M. Peripheral muscle weakness contributes to exercise limitation in COPD. Am J Respir Crit Care Med 1996;153:976-80.

35 Jakobsson $\mathbf{P}$, Jorfeldt L, Brundin A. Skeletal muscle metabolites and fibre types in patients with advanced chronic obstructive pulmonary disease (COPD), with and without chronic respiratory failure. Eur Respir J 1990;3:192-6.

36 Sala E, Roca J, Marrades RM, et al. Effects of endurance training on skeletal muscle bioenergetics in chronic obstructive pulmonary disease. Am J Respir Crit Care Med 1999;159:1726-34

37 Lacasse Y, Wong E, Guyatt GH, et al. Meta-analysis of respiratory rehabilitation in chronic obstructive pulmonary disease. Lancet 1996:348:1115-9.

38 Reardon J, Awad E, Normandin E, et al. The effect of comprehensive outpatient pulmonary rehabilitation on dyspnea. Chest 1994;105:1046-52.

39 Smith JC, Hill DW. Stability of parameter estimates derived from the power/ time relationship. Can J Appl Physiol 1993;18:43-7.

40 Noseda A, Carpiaux JP, Prigogine T, et al. Lung function, maximum and submaximum exercise testing in COPD patients: reproducibility over a long interval. Lung 1989;167:247-57. 